\title{
INTERVIEW
}

\section{An Interview with Dr. Vincenza Tudini from the University of South Australia}

Maria Luisa Malerba

Internet Interdisciplinary Institute (IN3), Open University of Catalonia (UOC), Barcelona, Spain

Text received 30 January 2014; final version 10 February 2014

Vincenza Tudini is a Senior Lecturer at the School of Communication, International Studies and Languages at the University of South Australia. She has a Ph.D. in Italian with a focus on critical analysis of contemporary narrative. Her more recent research and publications record is in the area of applied linguistics with a focus on Computer Mediated Communication. She has directed several projects in the area of Computer Assisted Language Learning (C.A.L.L.) including a project of the Australian Federation of Modern Language Teachers (AFMLTA) Language Resources on the Internet and a project of the Australian Language \& Literacy Council Implications of Technology for Language Teaching. She is currently working on several projects that research and develop online language teaching and learning.

INTERVIEWER: What online environments have you investigated so far in your projects and why? What online environments would deserve more investigation and why?

TUDINI: My main focus in my research investigation is text-chat because it is a particularly useful and appropriate teaching/learning tool for students of languages. When I talk about chat, I am not talking about audio chat and video chat, I am talking about dyadic text-chat rather than group chat. I have looked at group chat but only as a point of comparison with dyadic chat, where there are only two people in chat-rooms. Basically, when you are looking at using these tools for teaching and learning languages in particular, when you have got one of the participants who are in fact NNSs of the language that has been used, then it is important that the conversation is written, readable, so as you produce it, it appears on screen, and it is visually salient. This is a very 
important scaffold, which promotes learning for students of languages. As a first step to conversation, it is also a useful tool in its own right as a mode of communication that young people love to do, they go through phases, they like Facebook, they like the home, Facebook comments, they also like going into Facebook private chat. This is part of the way young people communicate. So that is my main focus because, having explored their possibilities, I believe that there is still a lot to be done because the web and the chat are changing and are giving us more information about how the interaction is produced. So there is still more work to be done, we do not know enough actually.

INTERVIEWER: This brings me to my next question. What kind of potential do online language learning communities such as Livemocha and Busuu have for fostering intercultural competence? Do you see their employment in telecollaboration projects? What role could they play?

TUDINI: I think that communities, which have been created for the purpose of language learning partnerships, are extremely important. In fact, we need more of this sort of communities also because I think that what is important there is to ensure that there is a level of safety for participants. When I first started introducing text-chat in my language classes at the university, it was really quite a new thing. No-one was doing it since it became very popular to do this, but at the beginning we were looking for existing online native speaker communities, so we used what was there and asked students keep going (as students of Italian in this case) and find NSs to chat with. But there was no monitoring, there was very limited monitoring and there were no restrictions on the kind of discussions that could happen, including sexual. Students had to navigate the various users, some of which had intentions that were other than learning. That was an experience for them, I still have some data from these early days. I do not know the two communities you mentioned but, personally, the communities that I find very useful are anything like SharedTalk. These communities should be the kind of site where people can go and feel that they are not going there because they are looking for virtual sex, but they have serious intentions in terms of "not getting married", because you have got that side as well. In terms of learning and establishing friendships, these communities should be the kind of 
site where it is possible to establish partnerships that can evolve into friendships, so language learning partnership where there is a reciprocal exchange. Normally, in these communities you are dealing with people who are bilingual, so they are used to moving between the two spaces, where there is the TL or the NL. Then all these sites need to be tested and tried and also researched. It is a wonderful thing that this is becoming more common but there is need to be monitoring on all of these sides. I had no complaints about SharedTalk, I had good evaluations from my students, it is now five years that I have been using it but I am sure that there is more to be discovered. We need investigation on these things.

INTERVIEWER: According to your experience in this field, what is the role of learner autonomy in the creation of opportunities for L2 use in CMC communication?

TUDINI: Learner autonomy is a big issue in this field. Obviously, the out-of-class interactions or in class interactions that are possible through voiced chat, text-chat and any kind of conversation or interaction online, requires learners to have a certain degree of autonomy. So it is not something that is occurring in a classroom with the teacher's guidance. Otherwise, what is the point? The aim was not just interacting with the teacher. Once you set up links with other institutions or online sites where learners can find their own partners who will help them, they are on their own, they are developing their autonomy. That is the role of the teachers, to develop their autonomy. Therefore, we cannot just cast them adrift, let them go and expect everything to be fine. What we need to do is ensure that there is constant dialogue with the learners on their out-of-class online experience. We need to be in contact. If you are having regular encounters in the classroom or online with the teacher you need to discuss episodes of misunderstanding. It is a matter of helping the students developing their autonomy; this is one of our duties but with a certain amount of caution because they still need you as a teacher and as an intercultural mediator. There are things they will not understand and you are there. That is why you have got the expert, that is why you have been employed and you have got your students. We cannot just expect students to be left on their own. Autonomy is a balancing act. 
INTERVIEWER: What kind of pedagogical tasks do you give to your students?

TUDINI: The pedagogical tasks have to be varied. So you give them plenty of choice. They need to be given some topics for discussion when they are thinking of the things to say. They also need tasks that promote intercultural reflection, in collaboration with their partners. We need students to ask questions of their partners, which encourages comparison of the two cultures, differences and similarities, so that the discussion is allowed to be interpersonal. By getting to know your partner and discussing, sometimes the conversation just takes off and the tasks that we set then become peripheral. Sometimes the student would say: "Look, I have had a fantastic chat with this person but have not used any of your tasks". And I would say: "That is fine, but we need to have some evidence that there has been intercultural reflection because this is a university course and we need to ensure that there is some thinking done about the two different cultures and that there has been reflection." It is not enough to connect people and expect that everything will just happen. Obviously, language use is a big plus, the fact that they are using the language and not necessarily in the classroom. So they are getting practice, which is a big thing. But, at the same time, we need to ensure that our discipline is being taught in a way that also ensures they are thinking, even linguistic thinking, thinking about the language they use. For example, one of the tasks that I also set for them is that they write a report; they do not just chat, what I have is an intercultural online project. This project entails two components. One of them is the actual chat session where they actually submit their best session. They do not submit everything, but they choose what they think are the most insightful, most interesting conversations for assessment. Otherwise, some of them write pages and pages and, as a teacher, you do not want to have to read pages and pages. So you get them to choose and you give them the number of pages and words. The second component is the intercultural reflection and that is where they discuss for example what they notice is different about Italy and Australia, Italians and Australians, what they think about certain aspects of society and how they live in these worlds, young people still live in the same way. But the other thing they do is that they become researchers of their own language learning; that actually allows them to 
document language learning episodes. In the same way that an expert of SLA would be doing, they have started to think about that, so they know all the new words that they learned; maybe they had discussions on that, they talk about the correction and their experience, all these things. They are looking at repair, they start looking at repair. And it is very nice, it is a good thing for them, they love it.

INTERVIEWER: Do you see a potential for language learning in CMC spontaneous interactions occurring in the informal learning realm, that is, in the absence of pedagogical tasks and without any form of assessment? For instance, I am thinking of the online chat of online communities designed for L2 learning, or any other chat like Skype and MSN, where learners are immersed in totally uncontrolled environments.

TUDINI: I see that as being something that is worthwhile if they want to do it for their language maintenance, which is fine. But if this activity is part of a university course, it has to be assessed; otherwise it is not seen as a serious task by either the institution or by the learners themselves at times. In general, the good language learners would do this because they are motivated, they do not need any incentive, they do not need to be assessed, it is something that they continue. Once you have started doing it at the university, there will be some things they do not keep up, but the contact with the NSs may continue for years, they become friends (also these things happen), they see each other, they visit each other and it is so good. But, definitely, this is a wonderful tool and I hope that people will take advantage of these tools even if they are not part of the university course. But, if they are part of a university course, we need to ensure that they are used regularly, that the process is guided and that they learn from it.

INTERVIEWER: Now a theoretical question. Is it possible to combine a social interactionist model of SLA (Gass, 1997) in the methodology with a theoretical framework based on socio-cultural theory (Vygotsky, 1978) without raising objections from the academic community? 
TUDINI: Yes, I think it is. I believe in combining methodologies. Just look at the example of CA for SLA, in a sense that it is exactly a combination which became a new theory. But, definitely, you have got two theories flowing together and improvement is happening methodologically. SLA is always picked up again, it is quite frequently in the discourse and I think that, with Vygotsky's theory, there is some aspect that is in common. You only have to look at the "comprehensible input" notion and the notion of ZPD. They are very similar, there is so much overlap between two constructs, that is very clear.

INTERVIEWER: This time a methodological question. Imagine that you are addressing a researcher or a PhD student who has collected a lot of online interactions. This researcher is overwhelmed by the huge quantity of material s/he has collected (text-chat and audiorecordings) in order to be analysed. How should s/he manage this huge amount of material? According to what criteria should s/he operate the selection and organize his/her data? For instance, in your book (Tudini, 2010) one of the criteria according to which you organize these data is the typology of assistance seeking and provision (selfinitiated self repair, self initiated other-repair, other-initiated self-repair, other-initiated other-repair). What about the following two criteria?

-Learner profile (learner taken as a single case study and considering his proficiency level, background, objectives, motivations for using the TL)

-Typology of interaction (text-chat, asynchronous private messages, audio recordings)

TUDINI: It is very common for researchers to collect a huge amount of data. I think that there needs to be a focus. One way that I have seen researchers handle the audio and text difference is to focus on differences in the way that these tools are used. If you focus, for example, on repair, you may want to see whether some existing studies can be replicated. We need to look, for example, at Jepson (2005), who looked at the repair as mainly related to pronunciation (he was using audio or video chat, but mostly the area was pronunciation). There is a book that is coming out by Christopher Jenks (2014, in press). He is mainly focused on voice chat.

I would be looking at how the repair differs. I would be focusing on a particular point and there is also need to be something that is relevant to participants. As you go through the 
data, you need to see patterns. Age, who they are, where they were born, their interest and background is not really relevant to CA. What is relevant is what the participants make relevant in the discussions. If age becomes relevant, it becomes a point of discussion, then you are orienting to that as a relevant issue that for this reason should be dealt with. In CA you have to be rigorous in what you do, you need to present as much information as you can about how the data was collected, who the participants were, ethics approval, all of those matters. But, as far as the other issues are concerned, you are looking at different tools audio and text, you need to find a point of focus and I would be looking at how these resources are used differently by participants of language learning. How are they different? Or how are they the same? What is the advantage of using text? Are they moving between text and audio-video or are they completely different participants? If they are the same participants, then you may look at how they are using the same tools, when they speak through voice chat, when they go back to text-chat.

INTERVIEWER: In Tudini (2010), you mention that you adopt Markee (2000)'s descriptors used in CA for SLA. Would you suggest any other model to look at and why?

TUDINI: Other models depend on what you are looking for. There are journals, such as Research on Language and Social Interaction, that is general and it is dedicated to CA and sometimes they also do CA for SLA. As far as models go, I guess that you need to decide according to online research models rather than models that are based on classroom interaction. You need to look at texts such as a new one that has just been published (Herring, Stein \& Virtanen, 2013). My own book (Tudini, 2010) is a good way to approach data.

INTERVIEWER: A question more directly related to Italian language and its application to your work. In you excerpts from the online interactions between NSs of English and NSs of Italian, you show that NSs of Italian make a wide use of Italian dialects, which play a remarkable role in Italian society still today, but which are not Italian. How do your Australian students react when they see Italian dialects? What kind of assistance are NSs of Italian able to provide (if any)? 
TUDINI: I see dialects as a necessary part of becoming speakers of the language. Learners come across different accents and different dialects and I am very supportive of this linguistic variety, it makes Italy emerge as a more interesting place. Students are very much aware of that. It is something that students negotiate; there are repairs that revolve around that. They ask questions, I see clarifications, they will go back, they find out what things mean, they say: "what does that mean, what are you talking about? Is that Italian or is it dialect?". So they learn. Normally, for what I can see in my data, the NSs do not use dialect with NNSs of Italian. I have not seen a lot of its use. When the teacher talks, s/he does not speak the language as s/he would with another NS. We speak differently maybe, especially when you are dealing with less proficient levels, it depends on the proficiency of the students. In the same way, native speakers engage in a kind of teacher talk, they adapt to the fact that probably the NNSs would not understand. In fact, they tend to test knowledge as well, when they are using a word that is potentially unclear, and they say: "Did you understand what I said?" They check understanding. That is just the way that it works.

INTERVIEWER: One last question about the future. Where do you think research should focus on for students thinking of starting a PhD?

TUDINI: At the moment there is a lot of talk about teaching online, also we need to investigate what is happening out of class and in the chat-room. I think we need more research on what happens using tools such as Skype between NSs and NNSs, students and native speakers of the target language. But also we need to understand what happens in an online classroom, because we, as teachers, have all been thrown in at the deep end and been asked to teach languages by using these online tools, which are quite wonderful to use, despite possible limitations. And students who are enrolled at a distance and cannot attend the class really appreciate them. We do not know enough about what is happening in that environment, how it differs, if it is going to be more constrained, and mostly we need to know what an ideal class size and configuration is to promote participation and interaction for learning. 


\section{References:}

Gass, S. (1997). Input, interaction and the second language learner. Mahwah, NJ: Lawrence Erlbaum.

Herring, S. C., Stein, D., \& Virtanen, T., Eds. (2013). Handbook of pragmatics of computermediated communication. Berlin: Mouton.

Jenks, C.J. (2014, in press). Social interaction in second language chat rooms. Edinburgh University Press.

Jepson, K. (2005). Conversations and negotiated interaction in text and voice chatrooms. Language Learning E Technology, 9(3), 79-98.

Markee, N. (2000). Conversation analysis. Routledge, New York.

Tudini, V. (2010). Online second language acquisition. Conversation analysis of online chat. London, Continuum International Publishing Group.

Vygotsky, L. S. (1978). Mind in society: The development of higher psychological processes. (M. Cole, Ed.). Harvard University Press.

Contact: Enza.Tudini@unisa.edu.au

Website: http://www.unisanet.unisa.edu.au/staff/Homepage.asp?Name=enza.tudini

\section{Author references:}

Maria Luisa Malerba is a PhD candidate at the Internet Interdisciplinary Institute (IN3), Open University of Catalonia (UOC). Her research revolves around informal second language learning in the online communities designed for language learning. Her investigation raises some questions about learners' construction of opportunities for L2 use and about the behaviours enacted by learners when inhabiting the communities.

Email: mmalerba@uoc.edu

\section{To cite this article:}

Malerba, M.L. (2014). An Interview with Professor Vincenza Tudini from the University of South Australia. Bellaterra Journal of Teaching \& Learning Language \& Literature, 7(1), 88-96. 